\title{
Decreased axial diffusivity within language connections: A possible biomarker of schizophrenia risk
}

\section{Citation}

Kubicki, M., M.E. Shenton, P.K. Maciejewski, P.E. Pelavin, K.J. Hawley, T. Ballinger, T. Swisher, et al. 2013. "Decreased Axial Diffusivity Within Language Connections: A Possible Biomarker of Schizophrenia Risk." Schizophrenia Research 148 (1-3) (August): 67-73. doi:10.1016/ j.schres.2013.06.014.

\section{Published Version}

doi:10.1016/j.schres.2013.06.014

\section{Permanent link}

http://nrs.harvard.edu/urn-3:HUL.InstRepos:28539569

\section{Terms of Use}

This article was downloaded from Harvard University's DASH repository, and is made available under the terms and conditions applicable to Other Posted Material, as set forth at http:// nrs.harvard.edu/urn-3:HUL.InstRepos:dash.current.terms-of-use\#LAA

\section{Share Your Story}

The Harvard community has made this article openly available.

Please share how this access benefits you. Submit a story.

Accessibility 


\title{
Decreased Axial Diffusivity within Language Connections: A Possible Biomarker of Schizophrenia Risk
}

\author{
M Kubicki ${ }^{1}$, ME Shenton ${ }^{1,2}$, PK Maciejewski ${ }^{3}$, PE Pelavin $^{1}$, KJ Hawley ${ }^{1}$, T Ballinger ${ }^{1}, \mathbf{T}$

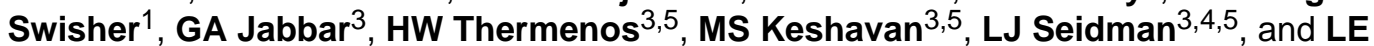 \\ DeLisi ${ }^{2,3}$ \\ ${ }^{1}$ Psychiatry Neuroimaging Laboratory, Brigham and Women's Hospital, Harvard Medical School, \\ Boston, MA, USA \\ ${ }^{2}$ VA Boston Healthcare System, Brockton, MA, United States \\ ${ }^{3}$ Harvard Medical School, Boston, MA, USA \\ ${ }^{4}$ Department of Psychiatry, Massachusetts General Hospital, Boston, MA, USA \\ ${ }^{5}$ Department of Psychiatry, Beth Israel Deaconess Medical Center, Boston, MA, USA; \\ Massachusetts Mental Health Center Division of Public Psychiatry, Boston, MA, USA
}

\begin{abstract}
Siblings of patients diagnosed with schizophrenia are at elevated risk for developing this disorder. The nature of such risk associated with brain abnormalities, and whether such abnormalities are similar to those observed in schizophrenia, remain unclear. Deficits in language processing are frequently reported in increased risk populations. Interestingly, white matter pathology involving fronto-temporal language pathways, including Arcuate Fasciculus (AF), Uncinate Fasciculus (UF), and Inferior Occipitofrontal Fasciculus (IOFF), are frequently reported in schizophrenia. In this study, high spatial and directional resolution diffusion MRI data was obtained on a 3T magnet from 33 subjects with increased familial risk for developing schizophrenia, and 28 control subjects. Diffusion Tractography was performed to measure white matter integrity within AF, UF, and IOFF. To understand these abnormalities, Fractional anisotropy (FA, a measure of tract integrity) and Trace (a measure of overall diffusion), were combined with more specific measures of axial diffusivity ( $\mathrm{AX}$, a putative measure of axonal integrity) and radial diffusivity (RD, a putative measure of myelin integrity). Results revealed a significant decrease in Trace within IOFF, and a significant decrease in AX in all tracts. FA and RD anomalies, frequently reported in schizophrenia, were not observed. Moreover, AX group effect was modulated by age, with
\end{abstract}

(C) 2013 Elsevier B.V. All rights reserved.

Corresponding Author: Marek Kubicki, MD, PhD; Psychiatry Neuroimaging Laboratory; 1249 Boylston Street, Boston, MA 02215; TEL: (617) 525-6117; FAX: (617) 525-6432; kubicki@bwh.harvard.edu.

Authors contributions

Dr. Kubicki designed the study, run the analyses and wrote first draft of the manuscript. Dr Maciejewski provided statistical expertise. Mrs Pelavin, Hawley, Jabbar, Ballinger, Swisher helped with data processing, literature searches, paper formatting. Drs. Shenton, Keshavan, Seidman and DeLisi helped with data interpretation. Drs Thermenos, Shenton and DeLisi helped with editing of the manuscript. All authors contributed to and have approved the final manuscript.

Disclosure/conflict of interest statement

This research was conducted in the absence of any commercial or financial relationships that could be construed as a potential conflict of interest.

Publisher's Disclaimer: This is a PDF file of an unedited manuscript that has been accepted for publication. As a service to our customers we are providing this early version of the manuscript. The manuscript will undergo copyediting, typesetting, and review of the resulting proof before it is published in its final citable form. Please note that during the production process errors may be discovered which could affect the content, and all legal disclaimers that apply to the journal pertain. 
increased risk subjects demonstrating a deviation from normal maturation trajectory. Findings suggest that familial risk for schizophrenia may be associated with abnormalities in axonal rather than myelin integrity, and possibly associated with disruptions in normal brain maturation. AX should be considered a possible biomarker of risk for developing schizophrenia.

\section{Keywords}

Increased Familial Risk; Schizophrenia; Diffusion Tensor Imaging; White Matter Maturation

\section{INTRODUCTION}

Schizophrenia is a major mental illness with a prevalence rate of approximately $1.4 \%$ and incidence rate of 0.16-0.42 per 1000 worldwide (Jablensky, 2000). Its peak age of onset is in early adulthood, and it is considered a heritable complex disorder; pathogenesis may be mediated by biological endophenotypes (Gottesman and Gould, 2003; Cannon et al., 2003). Some candidate genes that confer an elevated risk for schizophrenia have been identified, but are not yet considered definitive (Harrison and Owen, 2003). While there is evidence of progression, it has been suggested that the primary origin of brain anomalies is neurodevelopmental, predating any signs of illness (e.g., DeLisi, 1999; Lieberman, 1999; Pantelis et al., 2003).

Schizophrenia is characterized by wide-spread cognitive (for review see Pantelis and Maruff, 2002), structural (reviewed in Shenton et al., 2001), and functional deficits (reviewed in Gur and Gur, 2010). Many of these abnormalities, including altered language function and lateralization, cortical volume deficits, and deficits in white matter (WM) integrity, are already detectable at first psychotic episode or first psychiatric hospitalization (e.g., DeLisi, 1999; Kasai et al., 2003; Peters et al., 2010; Melonakos et al., 2011). There is also growing evidence of language deficits in those at familial (Rajarethinam et al., 2011) or clinical increased risk for schizophrenia (Li et al., 2007), and these deficits are thought to arise early and prior to schizophrenia onset (e.g., Pantelis et al., 2003), possibly dating back to early developmental problems as evidenced by delays in language acquisition and reading abilities (e.g., DeLisi, 1999).

Recent advances in neuroimaging, in particular the introduction of Diffusion Tensor Imaging in 1994 (DTI; Basser et al., 1994; Pierpaoli et al., 1996), make possible the quantitative in vivo analysis of WM integrity. DTI is an imaging method sensitive to the strength and direction of water diffusion within the brain. Early investigations suggested that DTI derived measures, such as Fractional Anisotropy (FA, a measure of WM integrity) and Trace (a measure of overall diffusion), are useful in detecting WM pathology. Also, in addition to nonspecific measures of FA and Trace, two other indices have been introduced. Axial Diffusivity (AX), which captures diffusion along the neuronal axons, and Radial Diffusivity (RD), which captures diffusivity perpendicular to the axons. These measures are demonstrated, in animal studies, to be more sensitive than FA or Trace alone as markers of axonal (AX) and myelin (RD) integrity (Song et al., 2003; Song et al., 2005; Harsan et al., 2006; Budde et al., 2008; Burzynska et al., 2010).

Of note, DTI is the most popular technique for investigating WM abnormalities in neuropsychiatric disorders, with over 200 publications in schizophrenia alone. Here, the majority of studies demonstrate FA decrease and MD increase, with recent studies also reporting associated RD decrease (e.g., Seal et al., 2008; Levitt et al., 2012). Anatomically, the majority of changes are reported in corpus callosum, and major fronto-temporal WM fiber tracts, including arcuate fasciculus (AF), cingulum bundle, uncinate fasciculus (UF) 
and inferior occipito-frontal fasciculus (IOFF; see reviews in Kubicki et al., 2007;

Kyriakopoulos et al., 2008; Peters et al., 2010; Melonakos et al., 2011). Interestingly, most of these fiber tracts are thought to provide communication and connectivity between brain regions involved in language processing (Duffau, 2008; Saur et al., 2008; Glasser and Rilling, 2008).

There have been very few published studies, however, that investigate WM integrity in those at familial high-risk for schizophrenia, and in contrast to the schizophrenia literature, results have been equivocal. Studies report either decreased FA (within Anterior Limb of the Internal Capsule- Munoz Maniega et al., 2008; Corpus Callosum and Cingulum BundleCamchong et al., 2009; frontal WM- Hoptman et al., 2008), or increased FA in those at high familial risk, compared with controls (frontal WM- Hoptman et al., 2008). Few additional studies also investigated subjects at clinical increased risk to develop schizophrenia (Ultra high risk, or prodromal), with similar discrepancies in their findings: widespread FA reductions (Carletti et al., 2012), no differences between ultra high-risk and control subjects (Peters et al., 2008), and FA increases (WM- Bloemen et al., 2010; AF- Boos et al., 2012). None of these used AX or RD measures, and only one study focused on a language related WM tract (AF), where increased, rather than decreased FA was reported. Since increased FA has not been consistently reported in the schizophrenia literature, the authors suggested that their findings might be related to a separate process, that constituted a risk to develop psychosis, but not psychosis itself (Boos et al., 2012). These findings, taken together, suggest the importance of investigating the integrity of fiber tracts involved in language processing in risk for schizophrenia. The aim of this study was to use state-of-the-art methodology to quantify diffusion tractography of AF, UF and IOFF, using FA, Trace, AX and RD. We applied these techniques to a relatively large and homogenous sample of subjects with a strong family history of schizophrenia, to delineate and understand further the biological nature of WM abnormalities associated with risk for schizophrenia.

\section{METHODS}

\section{Subject Recruitment and Evaluations}

"Familial increased risk" was defined as between the ages of 18-30 years and having at least 2 relatives with a psychiatric illness, where one was required to be a first-degree relative with a confirmed diagnosis of schizophrenia or schizoaffective disorder, and the other either another $1^{\text {st }}$ degree, $2^{\text {nd }}$ and/or $3^{\text {rd }}$ degree relative with a psychosis. Subjects came from chapters of The National Alliance on Mental Illness (NAMI). The Diagnostic Interview for Genetic Studies (DIGS; http://www.nimhgenetics.org/interviews/digs_4.0_bp) was used for all participants to determine lifetime presence of any Axis I or II psychiatric disorder and/or substance use (none of the subjects were diagnosed with substance abuse, however use of marijuana and alcohol in the past were not considered exclusion criteria). These interviews were performed in combination with the SIS (Structured Interview for Schizotypy). The SIS contains quantitative measures of each aspect of schizotypy, such as suspiciousness, social anxiety, magical thinking, etc. Premorbid (pre-prodromal) function was assessed using the Premorbid Adjustment Scale (Cannon-Spoor et al., 1982). A medical history was also taken and included history of medication.

Healthy Controls were matched to increased risk subjects on age, sex and ethnicity and recruited by advertisement in the same communities from which each increased risk subject lived. They were excluded if they had a family history of schizophrenia, schizoaffective disorder, bipolar disorder, any psychotic disorder, or suicide in a $1^{\text {st }}, 2^{\text {nd }}$ or $3^{\text {rd }}$ degree relative and also if they satisfied symptom criteria for a prodromal syndrome according to the Criteria of Prodrome Syndrome (COPS, see below). Hand preference was assessed using the Annett 23 item scale (Annett, 1985). Because recruitment was part of the larger effort 
focusing on language anomalies, individuals whose native language was not English were excluded. Because of language lateralization, and reported differences in diffusion indices between left and right-handed individuals (Catani and Mesulam, 2008), left-handed subjects were also excluded from the study. The study was explained to each subject and written informed consent obtained. The research protocol was approved by VABHS, Beth Israel Deaconess Hospital and Harvard Medical School IRBs.

\section{Data acquisition}

All MRI scans were acquired on a Siemens TRIO TIM 3.0 Tesla research dedicated fullbody scanner at Massachusetts Institute of Technology, equipped with a $40 \mathrm{mT} / \mathrm{m}$ gradient set. DTI scans were acquired using an echo planar imaging (EPI) DTI Tensor sequence. We used a double echo option to reduce eddy-current related distortions (Heid, 2000; Alexander et al., 1997). We also used a 32 Channel coil and parallel imaging using GRAPPA with speed-up factor of 2. We used Boston CIDAR (Center for Intervention Development and Applied Research) scanning protocol, where we acquired 60 directions with $b=700,10$ baseline scans with $b=0$. The following scanning parameters were used: TR $8000 \mathrm{~ms}$, TE $84 \mathrm{~ms}$, FOV $25.6 \mathrm{~cm}, 128 \times 128$ encoding steps, and $2 \mathrm{~mm}$ slice thickness (thus resulting in $2 \times 2 \times 2 \mathrm{~mm}^{3}$ voxel size), 64 axial slices were covering the whole brain. Total scan time for this sequence was 10 minutes.

\section{Data Processing}

DT Tractography-For delineation of UF, AF, and IOFF, we used a streamline tractography method, using Slicer 3D software. These tracts were chosen based on previous schizophrenia findings involving language connectivity (Mandonnet et al., 2007; Duffau, 2008). Tracts were seeded within manually drawn regions of interest (ROIs; drawn individually for each subject), and filtered through additional inclusion/exclusion ROIs, following the method described in Rosenberger et al., 2008. Next, tracts were generated using an eigenvector-tracking algorithm based on the fourth order Runge-Kutta method. A regularization scheme, which adds a small bias towards the previous tracking direction to the current tensor was used. The seed spacing was set at $1 \mathrm{~mm}$, with integration step set at $0.5 \mathrm{~mm}$. The tractography stopping criteria were as follows: Westin's linear measure (Westin et al., 1997) below 0.15 and tract curvature above 0.87 . Westin's linear measure, instead of FA, is routinely used in Slicer 3D to terminate tractography, in order to avoid the confound of using the same measure to construct fiber tracts, and to quantify their integrity. After fiber tracking, mean trace, FA, AX, and RD were calculated by integrating measures along each tract.

Anatomical criteria for ROI placement to extract IOFF, AF and UF are described in detail by us elsewhere (i.e., Rosenberger et al., 2008), and follow closely those by Catani and Thiebaut de Schotten, in their DTI atlas (Catani and Thiebaut de Schotten, 2008). Once ROIs were manually drawn for each subject separately, tract seeding was done from each ROI and tracts were filtered through other ROIs. To filter out extraneous fibers, additional, exclusion ROIs were traced for each tract. Tracts and their ROIs used for generating tracts are displayed on Figure 1.

After extraction, mean diffusion indices were calculated for each tract, and compared between groups (increased vs. low risk to develop schizophrenia). In addition, we have computed "genetic loading", which is a single score indicating contiguous genetic risk for developing schizophrenia (Glatt et al., 2006), and correlated with measure with axial diffusivity changes. Interestingly, only AX for the arcuate fasciuclus showed statistically significant relationship with genetic loading $(\mathrm{R}=-.286, \mathrm{P}=0.028)$, suggesting that anatomical changes, even though observed in all tracts, might not be related to genetic predisposition in 
the same way. Further studies are needed to investigate this issue. Also, in addition to group comparison, we explored age and gender effects, and the effects of age and gender interactions with group, for UF, AF, and IOFF for both the left and right hemispheres. Here, each tract was investigated separately using analysis of variance (ANOVA), first without covariates, then with gender as a fixed factor and linear term for age as a covariate.

Additionally, since the relationship between age and diffusion indices have been suggested to be nonlinear (Lebel et al., 2008; Lebel et al., 2012), we also ran the same ANOVA with a quadratic term for age as a covariate.

\section{RESULTS \\ Group Characteristic}

Thirty-three subjects with Increased Familial Risk to Develop Schizophrenia (HRs; 10 males and 23 females) and 26 healthy Controls with Low Familial Risk to Develop Schizophrenia (NCs; 11 males and 15 females) participated in the study. Mean age of participants was: 24.42 ( $\mathrm{SD}=2.93$ ) for $\mathrm{NCs}$, and 25.32 ( $\mathrm{SD}=2.97$ ) for HRs. There were no significant differences in gender $(\mathrm{P}=0.31)$, age $(\mathrm{P}=0.27)$, IQ $(\mathrm{P}=0.17)$, or education $(\mathrm{P}=0.35)$ between groups (independent sample t-tests) (See Table 1 for more details). There were no statistically significant group differences in any clinical/cognitive measures, or any correlations between diffusion measures and SIS scores.

\section{Hypothesis-driven comparison of UF, AF and IOFF}

Repeated Measures ANOVA with tracts (IOFF, UF and AF) and side (left and right) as within subject variables and group (HRs and $\mathrm{NCs}$ ), as between subject variables revealed a significant effect of group for $\mathrm{AX}(\mathrm{F}=6.01, \mathrm{df} 1=1, \mathrm{df} 2=58 ; \mathrm{p}=0.017)$, and Trace $(\mathrm{F}=4.28$, $\mathrm{df} 1=1, \mathrm{df} 2=58 ; \mathrm{p}=0.043)$, but not for $\mathrm{FA}(\mathrm{F}=0.14, \mathrm{df} 1=1, \mathrm{df} 2=58 ; \mathrm{p}=0.71)$, or $\mathrm{RD}(\mathrm{F}=2.60$, $\mathrm{df} 1=1, \mathrm{df} 2=58 ; \mathrm{p}=0.11$ ). No group $\mathrm{x}$ tract or group $\mathrm{x}$ side interactions were present for any measures. These results suggest that all three tracts on both sides show similar patterns of differences (Figure 2). To investigate further the direction of significant differences, independent sample t-tests were performed for AX and Trace for all three tracts. Here, AX was significantly decreased in all three tracts (AF- $\mathrm{p}=0.04 ; \mathrm{t}(1,58)=2.1$; IOFF- $\mathrm{p}=0.049$; $\mathrm{t}(1,58)=2.01$; UF- $\mathrm{p}=0.038 ; \mathrm{t}(1,58)=2.12$, while Trace was significantly decreased only in IOFF- $\mathrm{p}=0.033 ; \mathrm{t}(1,58)=2.18$; with other tracts showing non-significant trend towards decrease $(A F-p=0.167 ; t(1,58)=1.39 ; \mathrm{UF}-\mathrm{p}=0.113 ; \mathrm{t}(1,58)=1.61)$. Estimated effect sizes for $\mathrm{AF}$ and UF were larger for AX than for Trace ( $\mathrm{d}=0.54$ vs $\mathrm{d}=0.38)$.

To investigate further possible sources of AX variance, ANOVA with gender as a fixed factor and linear term for age as a covariate were performed for each tract. Age modified the effect of group on AX in the UF (interactions with age: $F=6.07$, df1=2, df2=53; $\mathrm{p}=0.004$ ), $\mathrm{AF}$ (interactions with age: $\mathrm{F}=3.97$, $\mathrm{df} 1=2, \mathrm{df} 2=53 ; \mathrm{p}=0.025$ ), and IOFF (interactions with age: $\mathrm{F}=3.35$, df $1=2$, df2=53; $\mathrm{p}=0.043$ ), and sex modified the effect of group in $\mathrm{AF}$ (interaction with sex: $\mathrm{F}=5.80$, df $1=1$, df $2=54 ; \mathrm{p}=0.019$ ), indicating that decrease in AF might be more pronounced in men compared with women (Figure 3). Finally, we attempted to model nonlinear trajectories of AX changes with age, trying to replicate previous studies looking at WM developmental trajectories (Lebel et al., 2012; Lebel and Beaulieu, 2011). Figure 4 shows results of this analysis, illustrating that differences in AX associated with group in all three tracts varies with age with maximum group differences in AX occurring between 26 and 28 years of age (Figure 4). This is despite the fact that there were no statistical differences between groups in age. 


\section{DISCUSSION}

Results of our study indicate that WM diffusion abnormalities within the language tracts are already present in nonpsychotic HR subjects. These abnormalities involve all three language tracts studied, and include decrease of diffusion predominantly in the direction parallel to the axons (AX).

To our knowledge, this is the first study to focus on major WM bundles involving the language system in those at increased familial risk to develop schizophrenia, and the first to use AX and RD in these tracts. The few studies that have applied these measures to schizophrenia report RD increase, and no AX changes (Seal et al., 2008; Levitt et al., 2012; Scheel et al., 2012). RD increase is shown, both in animal and clinical studies, to be associated with myelin alterations (Song et al., 2005; Klawiter et al., 2011). This, combined with findings of abnormalities in myelin thickness, oligodendrocyte size, and density observed post-mortem in schizophrenia (Uranova et al., 2004; Uranova et al., 2011) suggest that DTI findings in schizophrenia are likely indicators of myelin pathology (e.g., Konrad and Winterer, 2008). If RD increase is indeed an indicator of myelin abnormalities in patients with schizophrenia, our data does not support existence of such pathology in HR subjects. Instead, observed changes in AX were associated with axonal, rather than myelin alterations. In fact, the original study by Song that introduced AX and RD (Song et al., 2003), report decrease in Trace and AX, and no changes in RD associated with axonal damage, with changes in AX being the largest. Besides axonal loss, other pathological processes affecting axons have also been related to $\mathrm{AX}$, including changes in axonal size during brain healing (Harsan et al., 2006), or changes in tract compactness during brain tumor growth (Schonberger et al., 2006). Based on those reports, our results suggest possible changes in axonal number, size or compactness, as possible sources of diffusion changes. This would also suggest that myelin pathology (observed with DTI) develops later, due to psychosis or medication, possibly as a consequence of neuro-inflammation (Pasternak et al., 2012). Future longitudinal studies are needed to investigate further such interpretations.

It has been suggested that schizophrenia might be associated with pathological aging (Tang et al., 2009), or that it might alter brain maturation (Douaud et al., 2009). We have thus further investigated whether AX measures in HR subjects follow healthy maturation trajectory, or might be perhaps early indicators of deviations from such trajectory. Parenthetically, several DTI studies have observed that diffusion indices change nonlinearly with age, following a reversed $U$ shape, and such a pattern can be an indicator of brain development/maturation. Indeed, here, we were able to replicate such findings on our population of low-risk controls, demonstrating nonlinear (reversed U-shape) trajectory of AX changes with age, with a peak around 26-28 years of age (consistent with findings in Lebel et al., 2012; Lebel and Beaulieu, 2011). Interestingly, AX values in HR subjects did not follow such trajectory. Instead, they showed a linear, negative correlation with age. This was also the reason for the largest AX group differences (when adjusted for sex), observed around maturation peak (Figure 4). Since our samples are relatively small for such modeling, our results should be treated with caution. Nonetheless, if the AX differences observed in HR subjects are indeed due to alterations in brain maturation trajectory, this might offer new avenues in psychosis prediction, as such deviations might already be present at a much earlier age. Moreover, depending on the shape of maturation trajectory in HR (which we could not fully explore due to limited age ranges), discrepancies between results of previous HR investigations might be, at least to some degree, explained by differences in mean ages of studied populations (i.e., AX of HR subjects might be higher than AX of controls when measured at the age of 20, but lower when measured at the age of 27). Larger populations, with wider age ranges, as well as longitudinal studies are needed to understand better the association among age, risk, and psychosis. 
We acknowledge several limitations in this study. First, measures of axial and radial diffusivity can not be equated to any particular histological dimension (i.e., WheelerKingshott and Cerciniani 2009). Nevertheless, axonal changes remain the most plausible candidate, in light of the animal literature cited above. Thus, even though our results might indicate pathology associated with axons, such findings need to be replicated and validated using other techniques. Further, in order to understand better differences in maturation trajectories between healthy controls and HR subjects, larger populations with larger age range are needed. In addition, since all the tracts investigated in this study have shown some degree of maturation pathology, it is possible that not only language tracts, but all association tracts show similar changes. Thus studies investigating all fronto-temporal and interhemispheric connections are needed, in order to better understand this phenomenon. Another potential limitation of our study is the lack of a schizophrenia population for comparison. As discussed above, few increased risk studies have included patients with schizophrenia, and of those that have, show inconsistent findings. The latter is likely due to the fact that multiple factors related to schizophrenia (such as medication, psychosis, weight gain, diabetes, body temperature, head motion, cannabis and tobacco use, etc.) may all impact DTI measures, and could thus bias such comparisons. Our samples of increased and low risk subjects were matched for gender, however, since brains of males and females age differently, and we observed a gender effect on AX differences, it is possible that males carry higher genetic/familial risk for schizophrenia (Chiang et al., 2011). Larger populations that include both males and females should be studied in the future to understand further the role of gender in schizophrenia pathology.

\section{CONCLUSIONS}

Our findings suggest the presence of WM alterations in subjects with increased familial risk to develop schizophrenia. These abnormalities are likely not related to myelin integrity, observed frequently in schizophrenia studies. Instead, they are more likely related to caliber, number or compactness of axons, changes that occur as a result to alterations in brain maturation trajectory. Further studies are needed to understand better the nature of familial risk for schizophrenia.

\section{Acknowledgments}

Authors would also like to thank the families who donated their time to participate in these studies.

\section{Role of Funding Source:}

This study was supported, in part, by the National Alliance for Medical Image Computing (NA-MIC), supported through the National Institutes of Health Roadmap for Medical Research, Grant U54 EB005149 (MK, CFW, PG); VA Merit (MS), National Institute of Health (R01 M074794 to MK), NIMH-R21MH083205 (LED), MH 64023 (MSK, LS).

\section{References}

Alexander AL, Tsuruda JS, Parker DL. Elimination of eddy current artifacts in diffusion-weighted echo-planar images: the use of bipolar gradients. Magn Reson Med. 1997; 38(6):1016-1021. [PubMed: 9402204]

Annett, M. Left, Right, Hand and Brain: The Right-Shift Theory. Erlbaum; London: 1985.

Basser PJ, Mattiello J, LeBihan D. MR diffusion tensor spectroscopy and imaging. Biophys J. 1994; 66(1):259-267. [PubMed: 8130344]

Bloemen OJ, de Koning MB, Schmitz N, Nieman DH, Becker HE, de Haan L, Dingemans P, Linszen $\mathrm{DH}$, van Amelsvoort TA. White-matter markers for psychosis in a prospective ultra-high-risk cohort. Psychol Med. 2010; 40(8):1297-1304. [PubMed: 19895720] 
Boos HB, Mandl RC, van Haren NE, Cahn W, van Baal GC, Kahn RS, Hulshoff Pol HE. Tract-based diffusion tensor imaging in patients with schizophrenia and their non-psychotic siblings. Eur Neuropsychopharmacol. 2012

Budde MD, Kim JH, Liang HF, Russell JH, Cross AH, Song SK. Axonal injury detected by in vivo diffusion tensor imaging correlates with neurological disability in a mouse model of multiple sclerosis. NMR Biomed. 2008; 21(6):589-597. [PubMed: 18041806]

Burzynska AZ, Preuschhof C, Backman L, Nyberg L, Li SC, Lindenberger U, Heekeren HR. Agerelated differences in white matter microstructure: region-specific patterns of diffusivity. Neuroimage. 2010; 49(3):2104-2112. [PubMed: 19782758]

Camchong J, Lim KO, Sponheim SR, Macdonald AW. Frontal white matter integrity as an endophenotype for schizophrenia: diffusion tensor imaging in monozygotic twins and patients' nonpsychotic relatives. Front Hum Neurosci. 2009; 3:35. [PubMed: 19893757]

Cannon-Spoor HE, Potkin SG, Wyatt RJ. Measurement of premorbid adjustment in chronic schizophrenia. Schizophr Bull. 1982; 8(3):470-484. [PubMed: 7134891]

Cannon TD, van Erp TG, Bearden CE, Loewy R, Thompson P, Toga AW, Huttunen MO, Keshavan MS, Seidman LJ, Tsuang MT. Early and late neurodevelopmental influences in the prodrome to schizophrenia: contributions of genes, environment, and their interactions. Schizophr Bull. 2003; 29(4):653-669. [PubMed: 14989405]

Carletti F, Woolley JB, Bhattacharyya S, Perez-Iglesias R, Fusar Poli P, Valmaggia L, Broome MR, Bramon E, Johns L, Giampietro V, Williams SC, Barker GJ, McGuire PK. Alterations in white matter evident before the onset of psychosis. Schizophr Bull. 2012; 38(6):1170-1179. [PubMed: 22472474]

Catani M, Mesulam M. The arcuate fasciculus and the disconnection theme in language and aphasia: history and current state. Cortex. 2008; 44(8):953-961. [PubMed: 18614162]

Catani M, Thiebaut de Schotten M. A diffusion tensor imaging tractography atlas for virtual in vivo dissections. Cortex. 2008; 44(8):1105-1132. [PubMed: 18619589]

Chiang MC, McMahon KL, de Zubicaray GI, Martin NG, Hickie I, Toga AW, Wright MJ, Thompson PM. Genetics of white matter development: a DTI study of 705 twins and their siblings aged 12 to 29. Neuroimage. 2011; 54(3):2308-2317. [PubMed: 20950689]

DeLisi LE. Defining the course of brain structural change and plasticity in schizophrenia. Psychiatry Res. 1999; 92(1):1-9. [PubMed: 10688156]

Douaud G, Mackay C, Andersson J, James S, Quested D, Ray MK, Connell J, Roberts N, Crow TJ, Matthews PM, Smith S, James A. Schizophrenia delays and alters maturation of the brain in adolescence. Brain. 2009; 132(Pt 9):2437-2448. [PubMed: 19477963]

Duffau $\mathrm{H}$. The anatomo-functional connectivity of language revisited. New insights provided by electrostimulation and tractography. Neuropsychologia. 2008; 46(4):927-934. [PubMed: 18093622]

Glasser MF, Rilling JK. DTI tractography of the human brain's language pathways. Cereb Cortex. 2008; 18(11):2471-2482. [PubMed: 18281301]

Glatt SJ, Stone WS, Faraone SV, Seidman LJ, Tsuang MT. Psychopathology, personality traits, and social development of young first-degree relatives of schizophrenia patients. British Journal of Psychiatry. 2006; 189:337-345. [PubMed: 17012657]

Gottesman II, Gould TD. The endophenotype concept in psychiatry: etymology and strategic intentions. Am J Psychiatry. 2003; 160(4):636-645. [PubMed: 12668349]

Gur RE, Gur RC. Functional magnetic resonance imaging in schizophrenia. Dialogues Clin Neurosci. 2010; 12(3):333-343. [PubMed: 20954429]

Harrison PJ, Owen MJ. Genes for schizophrenia? Recent findings and their pathophysiological implications. Lancet. 2003; 361(9355):417-419. [PubMed: 12573388]

Harsan LA, Poulet P, Guignard B, Steibel J, Parizel N, de Sousa PL, Boehm N, Grucker D, Ghandour MS. Brain dysmyelination and recovery assessment by noninvasive in vivo diffusion tensor magnetic resonance imaging. J Neurosci Res. 2006; 83(3):392-402. [PubMed: 16397901]

Heid, O. Eddy current-nulled diffusion weighting. Proc Int Soc Mag Reson Med; Denver, CO. 2000. p. 799 
Hoptman MJ, Nierenberg J, Bertisch HC, Catalano D, Ardekani BA, Branch CA, Delisi LE. A DTI study of white matter microstructure in individuals at high genetic risk for schizophrenia. Schizophr Res. 2008; 106(2-3):115-124. [PubMed: 18804959]

Jablensky A. Epidemiology of schizophrenia: the global burden of disease and disability. Eur Arch Psychiatry Clin Neurosci. 2000; 250(6):274-285. [PubMed: 11153962]

Kasai K, Shenton ME, Salisbury DF, Onitsuka T, Toner SK, Yurgelun-Todd D, Kikinis R, Jolesz FA, McCarley RW. Differences and similarities in insular and temporal pole MRI gray matter volume abnormalities in first-episode schizophrenia and affective psychosis. Arch Gen Psychiatry. 2003; 60(11):1069-1077. [PubMed: 14609882]

Klawiter EC, Schmidt RE, Trinkaus K, Liang HF, Budde MD, Naismith RT, Song SK, Cross AH, Benzinger TL. Radial diffusivity predicts demyelination in ex vivo multiple sclerosis spinal cords. Neuroimage. 2011; 55(4):1454-1460. [PubMed: 21238597]

Konrad A, Winterer G. Disturbed structural connectivity in schizophrenia primary factor in pathology or epiphenomenon? Schizophr Bull. 2008; 34(1):72-92. [PubMed: 17485733]

Kubicki M, McCarley R, Westin CF, Park HJ, Maier S, Kikinis R, Jolesz FA, Shenton ME. A review of diffusion tensor imaging studies in schizophrenia. J Psychiatr Res. 2007; 41(1-2):15-30. [PubMed: 16023676]

Kyriakopoulos M, Bargiotas T, Barker GJ, Frangou S. Diffusion tensor imaging in schizophrenia. Eur Psychiatry. 2008; 23(4):255-273. [PubMed: 18524546]

Lebel C, Beaulieu C. Longitudinal development of human brain wiring continues from childhood into adulthood. J Neurosci. 2011; 31(30):10937-10947. [PubMed: 21795544]

Lebel C, Gee M, Camicioli R, Wieler M, Martin W, Beaulieu C. Diffusion tensor imaging of white matter tract evolution over the lifespan. Neuroimage. 2012; 60(1):340-352. [PubMed: 22178809]

Lebel C, Walker L, Leemans A, Phillips L, Beaulieu C. Microstructural maturation of the human brain from childhood to adulthood. Neuroimage. 2008; 40(3):1044-1055. [PubMed: 18295509]

Levitt JJ, Alvarado JL, Nestor PG, Rosow L, Pelavin PE, McCarley RW, Kubicki M, Shenton ME. Fractional anisotropy and radial diffusivity: diffusion measures of white matter abnormalities in the anterior limb of the internal capsule in schizophrenia. Schizophr Res. 2012; 136(1-3):55-62. [PubMed: 22019073]

Li X, Branch CA, Bertisch HC, Brown K, Szulc KU, Ardekani BA, DeLisi LE. An fMRI study of language processing in people at high genetic risk for schizophrenia. Schizophr Res. 2007; 91(13):62-72. [PubMed: 17306963]

Lieberman JA. Is schizophrenia a neurodegenerative disorder? A clinical and neurobiological perspective. Biol Psychiatry. 1999; 46(6):729-739. [PubMed: 10494440]

Mandonnet E, Nouet A, Gatignol P, Capelle L, Duffau H. Does the left inferior longitudinal fasciculus play a role in language? A brain stimulation study. Brain. 2007; 130(Pt 3):623-629. [PubMed: 17264096]

Melonakos ED, Shenton ME, Rathi Y, Terry DP, Bouix S, Kubicki M. Voxel-based morphometry (VBM) studies in schizophrenia-can white matter changes be reliably detected with VBM? Psychiatry Res. 2011; 193(2):65-70. [PubMed: 21684124]

Munoz Maniega S, Lymer GK, Bastin ME, Marjoram D, Job DE, Moorhead TW, Owens DG, Johnstone EC, McIntosh AM, Lawrie SM. A diffusion tensor MRI study of white matter integrity in subjects at high genetic risk of schizophrenia. Schizophr Res. 2008; 106(2-3):132-139. [PubMed: 18849149]

Pantelis C, Maruff P. The cognitive neuropsychiatric approach to investigating the neurobiology of schizophrenia and other disorders. J Psychosom Res. 2002; 53(2):655-664. [PubMed: 12169340]

Pantelis C, Yucel M, Wood SJ, McGorry PD, Velakoulis D. Early and late neurodevelopmental disturbances in schizophrenia and their functional consequences. Aust N Z J Psychiatry. 2003; 37(4):399-406. [PubMed: 12873323]

Pasternak O, Westin CF, Bouix S, Seidman LJ, Goldstein JM, Woo TU, Petryshen TL, MesholamGately RI, McCarley RW, Kikinis R, Shenton ME, Kubicki M. Excessive Extracellular Volume Reveals a Neurodegenerative Pattern in Schizophrenia Onset. J Neurosci. 2012; 32(48):1736517372. [PubMed: 23197727] 
Peters BD, Blaas J, de Haan L. Diffusion tensor imaging in the early phase of schizophrenia: what have we learned? J Psychiatr Res. 2010; 44(15):993-1004. [PubMed: 20554292]

Peters BD, de Haan L, Dekker N, Blaas J, Becker HE, Dingemans PM, Akkerman EM, Majoie CB, van Amelsvoort T, den Heeten GJ, Linszen DH. White matter fibertracking in first-episode schizophrenia, schizoaffective patients and subjects at ultra-high risk of psychosis. Neuropsychobiology. 2008; 58(1):19-28. [PubMed: 18781087]

Pierpaoli C, Jezzard P, Basser PJ, Barnett A, Di Chiro G. Diffusion tensor MR imaging of the human brain. Radiology. 1996; 201(3):637-648. [PubMed: 8939209]

Rajarethinam R, Venkatesh BK, Peethala R, Phan KL, Keshavan M. Reduced activation of superior temporal gyrus during auditory comprehension in young offspring of patients with schizophrenia. Schizophr Res. 2011; 130(1-3):101-105. [PubMed: 21684722]

Rosenberger G, Kubicki M, Nestor PG, Connor E, Bushell GB, Markant D, Niznikiewicz M, Westin CF, Kikinis R, AJS, McCarley RW, Shenton ME. Age-related deficits in fronto-temporal connections in schizophrenia: a diffusion tensor imaging study. Schizophr Res. 2008; 102(1-3): 181-188. [PubMed: 18504117]

Saur D, Kreher BW, Schnell S, Kummerer D, Kellmeyer P, Vry MS, Umarova R, Musso M, Glauche V, Abel S, Huber W, Rijntjes M, Hennig J, Weiller C. Ventral and dorsal pathways for language. Proc Natl Acad Sci U S A. 2008; 105(46):18035-18040. [PubMed: 19004769]

Scheel M, Prokscha T, Bayerl M, Gallinat J, Montag C. Myelination deficits in schizophrenia: evidence from diffusion tensor imaging. Brain Struct Funct. 2012

Schonberger RB, Worden WS, Shahmohammadi K, Menn K, Silverman TJ, Stout RG, Shelley KH, Silverman DG. Topical non-iontophoretic application of acetylcholine and nitroglycerin via a translucent patch: a new means for assessing microvascular reactivity. Yale J Biol Med. 2006; 79(1):1-7. [PubMed: 17876370]

Seal ML, Yucel M, Fornito A, Wood SJ, Harrison BJ, Walterfang M, Pell GS, Pantelis C. Abnormal white matter microstructure in schizophrenia: a voxelwise analysis of axial and radial diffusivity. Schizophr Res. 2008; 101(1-3):106-110. [PubMed: 18262770]

Shenton ME, Dickey CC, Frumin M, McCarley RW. A review of MRI findings in schizophrenia. Schizophr Res. 2001; 49(1-2):1-52. [PubMed: 11343862]

Song SK, Sun SW, Ju WK, Lin SJ, Cross AH, Neufeld AH. Diffusion tensor imaging detects and differentiates axon and myelin degeneration in mouse optic nerve after retinal ischemia. Neuroimage. 2003; 20(3):1714-1722. [PubMed: 14642481]

Song SK, Yoshino J, Le TQ, Lin SJ, Sun SW, Cross AH, Armstrong RC. Demyelination increases radial diffusivity in corpus callosum of mouse brain. Neuroimage. 2005; 26(1):132-140. [PubMed: 15862213]

Tang B, Chang WL, Lanigan CM, Dean B, Sutcliffe JG, Thomas EA. Normal human aging and earlystage schizophrenia share common molecular profiles. Aging Cell. 2009; 8(3):339-342. [PubMed: 19245676]

Uranova NA, Vikhreva OV, Rachmanova VI, Orlovskaya DD. Ultrastructural alterations of myelinated fibers and oligodendrocytes in the prefrontal cortex in schizophrenia: a postmortem morphometric study. Schizophr Res Treatment. 2011; 2011:325789. [PubMed: 22937264]

Uranova NA, Vostrikov VM, Orlovskaya DD, Rachmanova VI. Oligodendroglial density in the prefrontal cortex in schizophrenia and mood disorders: a study from the Stanley Neuropathology Consortium. Schizophr Res. 2004; 67(2-3):269-275. [PubMed: 14984887]

Westin CF, Peled S, Gudbjartsson H, Kikinis R, Jolesz FA. Geometrical diffusion measures for MRI from tensor basis analysis. Proceedings of ISMRM. 97:1742.

Wheeler-Kingshott CA, Cercignani M. About "axial" and "radial" diffusivities. Magn Reson Med. 2009 May; 61(5):1255-60. [PubMed: 19253405] 

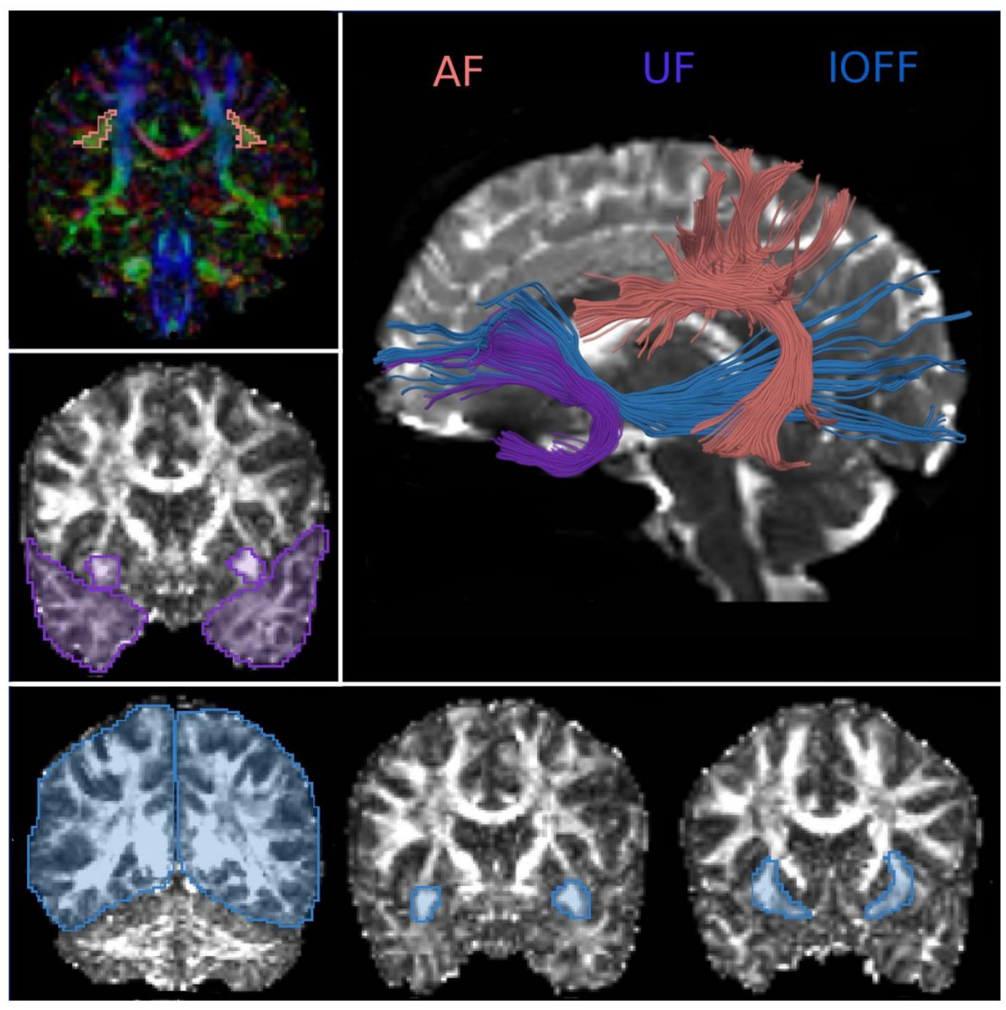

Figure 1.

Diffusion Tractography was used to extract three white matter bundles of language system. Uncinate Fasciculus (in teal), Arcuate Fasciculus (in orange) and Inferior Occipito-frontal Fasciuclus (in blue). 

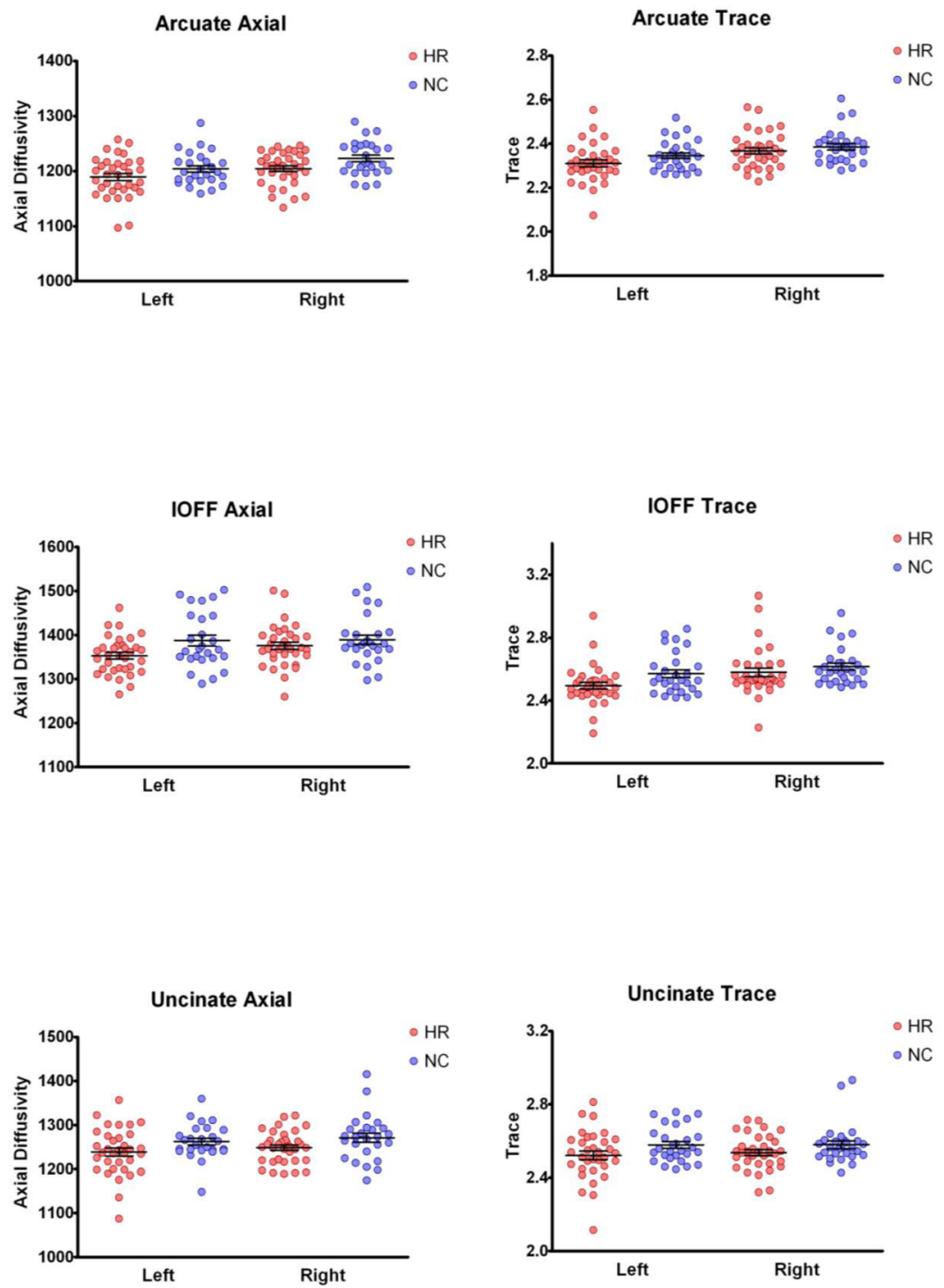

Figure 2.

Plots of Axial Diffusivity and Trace measurements in three tracts of interest obtained in subjects at risk to develop schizophrenia (HR- red), and controls (NC-blue). 


\section{Arcuate Axial (Left) Adjusted for Age}

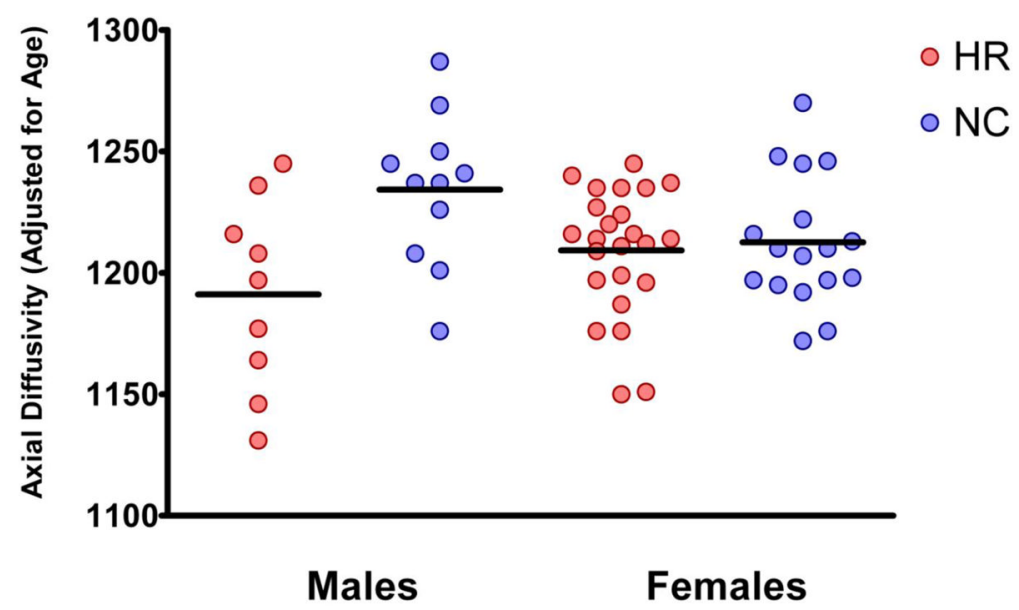

Figure 3.

Plot of Axial Diffusivity measure differences between subjects at risk (in red) and controls (in blue), when statistically corrected for age. 
Arcuate Axial (Right) Adjusted for Gender

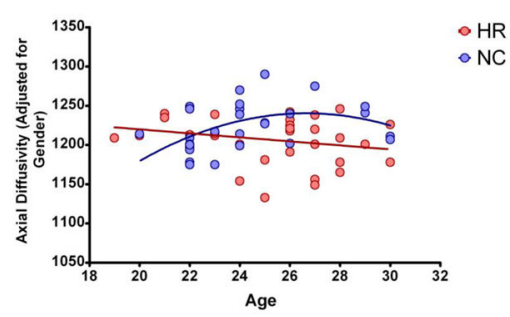

IOFF Axial (Right) Adjusted for Gender

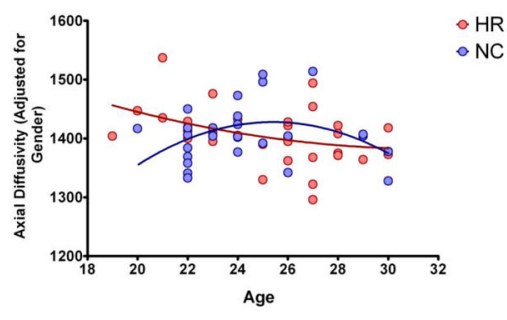

UF Axial (Right) Adjusted for Gender

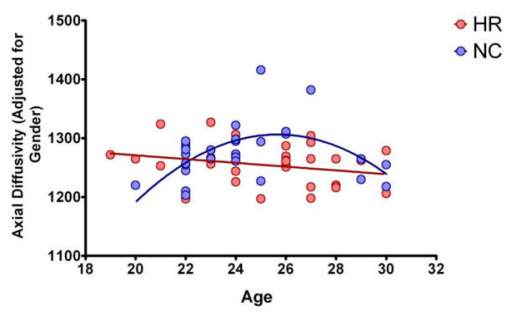

Figure 4.

Trajectories of Axial Diffusivity changes with age (when statistically corrected for gender), for subjects at risk (in red), and controls (in blue). 


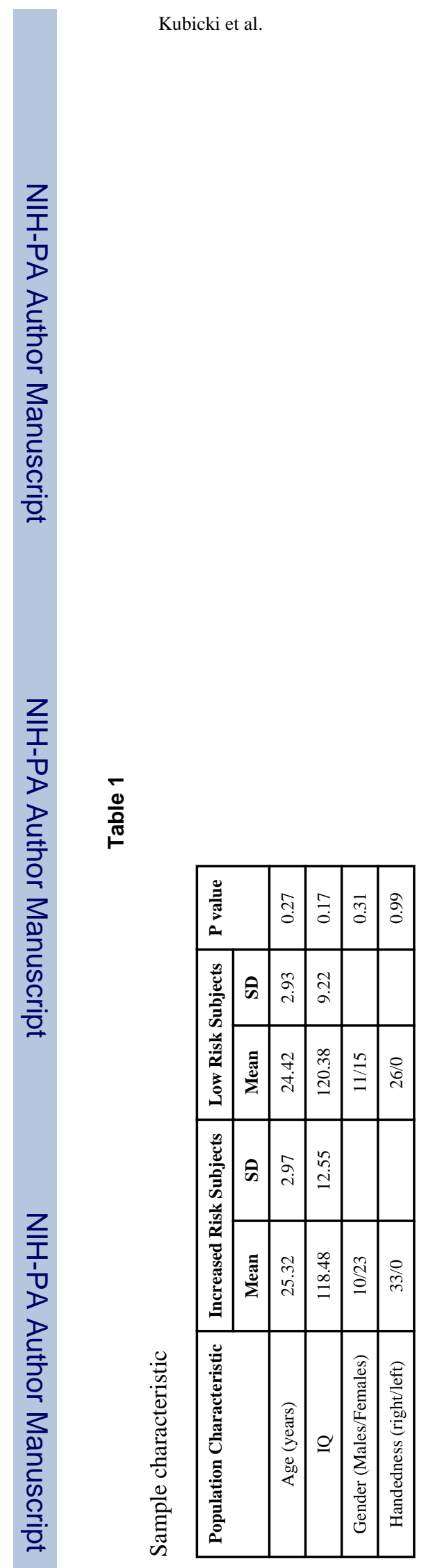

Schizophr Res. Author manuscript; available in PMC 2014 August 01. 